\title{
TAZE KARİDESLERİN RAF ÖMRÜNÜN UZATILMASINDA SOĞAN KABUĞU EKSTRAKTININ ETKİSI
}

\author{
İlknur Uçak* \\ Niğde Ömer Halisdemir Üniversitesi, Tarım Bilimleri ve Teknolojileri Fakültesi, Niğde, Türkiye
}

Geliş / Received: 07.01.2019; Kabul / Accepted: 14.02.2019; Online bask1 / Published online: 10.03.2019

Uçak, İ. (2019). Taze karideslerin raf ömrünün uzatılmasında soğan kabuğu ekstraktının etkisi. GID $A$ (2019) 44 (2): 226-237 doi: 10.15237/gida.GD19017

Uçak, I. (2019). The effects of onion peel extract in preventing shelf life of fresh shrimp. GIDA (2019) 44 (2): 226-237 doi: 10.15237/gida.GD19017

\section{ÖZ}

Bu çalısmada japon karidesi (Penaeus japonicus) ve yeşil kaplan karideslerinin (Penaeus semisulcatus) raf ömrünün uzatılması amacıyla soğan kabuğu ekstraktının etkileri araştırılmıştır. Baş ve kabukları ayrılmış olan karides etleri $\% 8$ oranında soğan kabuğu ekstraktı ile muamele edilmiş ve 8 gün $4 \pm 1^{\circ} C^{\prime}$ de depolanmıştır. Kontrol gruplarının toplam uçucu bazik azot (TVB-N) ve tiyobarbitürikasit (TBARS) değerleri ekstrakt ile muamele edilen gruplardan yüksek bulunmuştur. $\mathrm{pH}$ değerleri tüm gruplarda depolamanın sonuna kadar artış göstermiş, ancak bu artış kontrol gruplarında daha yüksek oranda tespit edilmiştir. Toplam canlı sayısı (TVC) ve toplam psikrofilik canlı sayısı (PBC) başlangıçta japon karidesi ve yeşil kaplan karideslerinde sırası ile 2.95; $2.68 \log \mathrm{kob} / \mathrm{g}$ ve $3.28 ; 2.95 \mathrm{log} \mathrm{kob} / \mathrm{g}$ bulunmuş ve bu değerler depolama sonunda artış göstermiştir. Soğan kabuğu ekstraktı ile muamele edilen karideslerde TVC ve PBC değerleri depolama süresince $7 \mathrm{log} \mathrm{kob} / \mathrm{g}$ limit değerini aşmamıştır. Bu çalışma sonuçları soğan kabuğu ekstraktının karideslerde kimyasal, mikrobiyal ve duyusal kalitenin korunmasında etkili bir doğal katkı maddesi olarak kullanılabileceğini göstermektedir.

Anahtar kelimeler: Karides, soğan kabuğu ekstraktı, mikrobiyal kalite, TVB-N, duyusal kalite

\section{THE EFFECTS OF ONION PEEL EXTRACT IN PREVENTING SHELF LIFE OF FRESH SHRIMP}

\begin{abstract}
In this study, the effects of onion peel extract was investigated in order to increase the shelf life of japanese shrimp (Penaeus japonicus) and green tiger shrimp (Penaeus semisulcatus). Decapitated shrimps were treated with $8 \%$ onion peel extract and stored at $4 \pm 1{ }^{\circ} \mathrm{C}$ for 8 days. The total volatile basic nitrogen (TVB-N) and thiobarbituric acid (TBARS) values of the control groups were found higher than those of the extract treated groups. The $\mathrm{pH}$ values showed increase in all groups until at the end of storage, but this increase was higher than those of the controls. The initial total viable count (TVC) and total psychrophilic bacteria count (PBC) were found as 2.95; 2.68 and 3.28; $2.95 \mathrm{log} \mathrm{cfu} / \mathrm{g}$ in japanese and green tiger shrimp, respectively, and these values showed increase at the end of the storage. TVC and PBC counts of the shrimps treated with onion peel extract did not exceed the limit value of $7 \log \mathrm{cfu} / \mathrm{g}$ during the storage period. Based on the results of this study, it might be thought that onion peel extract can be used as an effective natural additive for preserving chemical, microbiological and sensory quality of shrimps.
\end{abstract}

Keywords: Shrimp, onion peel extract, microbiological quality, TVB-N, sensory quality

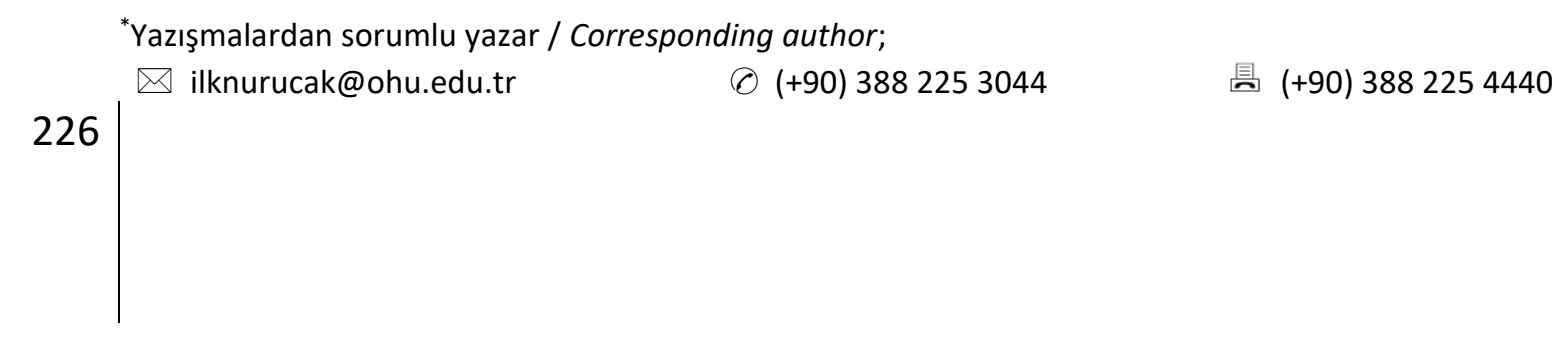




\section{GİRIŞ}

Crustacea sinıfinın Decapoda takımında yer alan karidesler, ekonomik değeri yüksek olan kabuklu su ürünlerindendir (Salman, 1995). Karidesler protein, serbest amino asitler ve omega-3 yağ asitleri bakımından oldukça zengindir. Ancak, zengin besin kompozisyonunun yanında bozulmaya da oldukça hassas olup sinırlı raf ömrüne sahiptir. Post-mortem depolama boyunca enzimatik ve mikrobiyolojik aktiviteler nedeni ile çok çabuk bozulabilen (Aşık ve Candoğan, 2014) karideslerin yakalandiktan sonra kısa bir süre içinde düşük sıcaklıklarda korunmaları, dondurulmaları veya işlenmeleri gerekmektedir. Karideslerde tazeliğin korunması ve raf ömrünün artırılması amac1 ile çeşitli antioksidan ve antimikrobiyal koruyucular kullanılmaktadır (Gökoğlu ve Yerlikaya, 2008; Nirmal ve Benjakul, 2011; Nirmal ve Benjakul, 2012). Ancak, tüketicilerin doğal ürünlere olan talebi ve sentetik koruyucular hakkındaki endişeleri nedeni ile yapılan çalışmalar yeni doğal kaynakların arayışı üzerine odaklanmaktadır.

Son yıllarda, gıda atıklarının ve yan ürünlerinin değerlendirilmesi ve bu ürünlerin gidaların raf ömrünü uzatmada antioksidan ve antimikrobiyal olarak endüstriyel kullanımlarına olan ilgi artmaktadır. Soğan (Allium cepa) çok yönlü bir sebze olup hem taze hem de işlenmiş olarak tüketilebilmektedir. Ancak yüksek oranda flavonoid içeren soğan kabukları, soğanların işlenmesi sırasında atılmaktadır. Bu nedenle soğan kabuğu, bir gıda endüstrisi atığ1 olarak değerlendirilmekte ve uygun koşullarda atılmadığ1 takdirde çevresel kirliliğe neden olabilmektedir (Ifesan, 2017). Ayrıca soğan kabuğunun soğandan daha yüksek miktarda flavonoid (özellikle kuarsetin) içerdiği de bildirilmiştir (Cook ve Samman, 1996). Soğan kabuğunun antioksidan ve antimikrobiyolojik etkileri ile ilgili çeşitli çalışmalar yapılmıştır (Sing vd., 2009; Nile vd., 2017; Kim vd., 2014; Ifesan, 2017). Ifesan (2017) soğan kabuğunun $\% 80$ etanol ile esktraksiyonu sonucunda toplam fenolik madde içeriğini 664.3 $\mu \mathrm{g} \mathrm{ml} / \mathrm{GA}$ olarak bulmuştur. Bir başka çalışmada soğan kabuğunun $\% 60$ ve $\% 80$ etanolik ekstraksiyonu sonucu toplam fenolik madde içeriği sırası ile 549.2 ve $608.4 \mathrm{mg} \mathrm{GA} / \mathrm{g}$ ve antioksidan madde içeriği ise sırası ile 100.1 ve $50.2 \mu \mathrm{mol}$ TEAC/g olarak bulunmuştur (Viera vd., 2017).

Soğan kabuğunun tüm bu özellikleri göz önünde bulundurulduğunda, sentetik koruyuculara karş1 alternatif doğal bir koruyucu olabileceği düşünülmektedir. Bu amaçla bu çalışmada, soğan kabuğu ekstraktının karideslerde soğuk depolama boyunca meydana gelen biyokimyasal ve mikrobiyolojik bozulmaları önlemede etkisinin araştırılması hedeflenmiştir.

\section{MATERYAL VE YÖNTEM}

Soğan kabuğu ekstraktının hazırlanması

Soğan kabukları, Niğde ilinde yerel marketten toplanmış ve laboratuvara getirilerek iki kez çeşme suyu ile yıkanmıştır. Yıkanan soğan kabukları $40^{\circ} \mathrm{C}$ 'ye ayarlanmış etüvde 48 saat süre ile kurutulmuş ve daha sonra blender yardımı ile toz haline getirilmiştir. Toz haline getirilen soğan kabukları erlenlere alınarak üzerine etanol çözeltisi (\%70) eklenmiş ve Tabaraki vd. (2012)' nin belirttiği yönteme göre ultrasonik destekli ekstraksiyon gerçekleştirilmiştir. Soğan kabuğu etanol oranı 1:10, $\mathrm{g} / \mathrm{ml}$ olarak belirlenmiştir. Daha sonra ekstrakte edilen örmekler filtre kağıdı ile süzülerek rotary evaporatörde (IKA, HB-10 digital, Germany) $45^{\circ} \mathrm{C}$ 'de uçurularak soğan kabuğu ekstraktları elde edilmiştir. Ekstraktlar, kullanılincaya kadar $-80^{\circ} \mathrm{C}$ derin dondurucuda (Symphony, VWR DW) muhafaza edilmiştir.

\section{Örneklerin hazırlanmas1}

Çalısmada, japon karidesi (JK) (Penaeus japonicus) ve yeşil kaplan karidesi (YK) (Penaeus semisulcatus) olmak üzere iki farklı tür karides kullanılmıştır. Karidesler Mersin ili limanından aynı gün yakalanmış olarak temin edilmiş ve yaklaşık 2 saat uzaklıkta bulunan Niğde Ömer Halisdemir Üniversitesi Tarım Bilimleri ve Teknolojileri Fakültesi laboratuvarına buz içerisinde getirilmiştir. Örneklerin ortalama ağırlı ve boyları siras1 ile japon karidesinde $15.5 \pm 1.32 \mathrm{~cm}$ ve $24 \pm 1.16 \mathrm{~g}$, yeşil kaplan karidesinde $14.5 \pm 0.35 \mathrm{~cm}$ ve $22 \pm 2.43 \mathrm{~g}$ olarak ölçülmüştür. Karidesler baş ve kabuk kısımları alındıktan sonra yıkanmış ve ön denemeler sonucu belirlenen $\% 8(\mathrm{ml} / \mathrm{g})$ oranında soğan kabuğu ekstraktı ile muamele edilmiştir. Ön 
denemeler ile belirlenen bu oran karides etinin koku ve görünüş özellikleri üzerinde minimum olumsuz etkiye sahip olmuştur. Bir grup kontrol olarak ayrılmıştır. Tüm örnekler strafor tabaklar içerisine koyularak streç film ile kaplanarak $4 \pm 1^{\circ} \mathrm{C}$ 'de depolanmıştır.

\section{Toplam uçucu bazik azot (TVB-N) tayini}

Homojenize edilen $10 \mathrm{~g}$ örneklerin uçucu baz içerikleri su buharı destilasyonu uygulanarak ayrılmış ve ayrılan bu bazlar $0.1 \mathrm{~N} \mathrm{HCl}$ içerisinde toplanmıştır. Toplanan destilatlar $0.1 \mathrm{~N} \mathrm{NaOH}$ ile titre edilmiş ve TVB-N miktarı mg/100 g olarak hesaplanmıştır (Schormüller, 1968).

\section{Tiyobarbitürikasit (TBARS) analizi}

Tiyobarbitürikasit değeri tayini Tarladgis vd. (1960) yöntemine göre yapılmıştır. $10 \mathrm{~g}$ karides eti alınarak $2.5 \mathrm{ml} \mathrm{HCl} \mathrm{(1:2} \mathrm{HCl:saf} \mathrm{su)} \mathrm{ile} \mathrm{su} \mathrm{buhar1}$ destilasyonu yapılmıştır. Elde edilen destilttan 5 $\mathrm{ml}$ alınıp $5 \mathrm{ml}$ TBA reaktifi solüsyonu $(0.288$ $\mathrm{g} / 100 \mathrm{ml}$ ) ile karıştırılmış ve reaksiyona girmesi amaciyla $110{ }^{\circ} C^{\prime}$ ye ayarlanmış su banyosunda 35 $\mathrm{dk}$ kaynatılmıştır. Hızla soğutulan örnekler, 538 $\mathrm{nm}$ dalga boyunda spektrofotometrik olarak ölçülerek sonuçlar mg malondialdehit/kg örnek olarak ifade edilmiştir.

\section{Mikrobiyolojik analizler}

Örneklerden alınan $10 \mathrm{~g}$ üzerine $90 \mathrm{ml}$ ringer solüsyonu eklenmiş ve stomacher yardımı ile $60 \mathrm{~s}$ homojenize edilmiştir. Aynı homojenattan diğer dilüsyon serileri hazırlanmıştır. Bakterilerin sayımı için uygun dilüsyonlardan ekim yapılmıştır. Tüm mikrobiyal analizler $0,1 \mathrm{ml}$ dilüsyon sıvısı alınarak yayma ekim şeklinde yapılmıştır. Toplam mezofil ve toplam psikrofil bakteri sayımında Plate Count Agar (PCA) kullanılmış ve sırası ile $35^{\circ} \mathrm{C}$ 'de 2 gün ve $7^{\circ} \mathrm{C}$ de 10 gün inkübe edilmiştir.

\section{pH ölçümü}

$\mathrm{pH}$ ölçümü için $\mathrm{pH}$ elektrodu saf su ile hazırlanan homojenata (1:1) daldırılmıştır. Tüm ölçümler, $\mathrm{pH}$ metre (Thermo Scientific Orion 2-star, Germany) kullanılarak oda sıcaklığında $\left(24 \pm 1^{\circ} \mathrm{C}\right)$ gerçekleştirilmiştir.

\section{Duyusal değerlendirme}

Karides örneklerinin duyusal değerlendirmesi Maqsood ve Benjakul (2011) tarafindan belirlenen yöntemde küçük modifikasyonlar yapilarak gerçekleştirilmiştir. Yaşları 25-35 arasında değişen 10 adet panelist kullanılarak oda koşullarında gün 1şığı altında duyusal değerlendirme yapılmıştır. Örnekler koku, tekstür, renk, görünüş ve genel beğeni yönlerinden 9 puanlık hedonik skala kullanılarak analiz edilmiştir. 9-7 "çok iyi", 6.9-4.0 "iyi", 3.9-1.0 "bozulmuş" olarak değerlendirilmiştir (Amerina vd., 1965).

\section{İstatistiksel analiz ve değerlendirmeler}

Çalışma iki tekerrürlü olarak gerçekleştirilmiş ve elde edilen sonuçlara varyans analizi uygulanmıştır. Gruplar arasındaki farklilıklar Duncan çoklu karşılaştırma testine tabi tutulup, \%5 önem düzeyinde karşılaştırılmıştır. İstatistiksel analizler için SAS yazılımı (Statistical Analysis System, Cary, NC, USA) kullanılmıştır.

\section{SONUÇ VE TARTIŞMA}

Depolama boyunca toplam uçucu bazik azot (TVB-N) miktarında meydana gelen değişimler

Depolama süresince soğan kabuğu ekstraktı eklenmiş japon karidesi ve yeşil kaplan karidesinin TVB-N değerlerinde meydana gelen değişim Şekil 1'de verilmiştir. Depolamanın başında TVB-N değerleri japon karidesi ve yeşil kaplan karidesinde sirasi ile 25.61 ve $20.26 \mathrm{mg} / 100 \mathrm{~g}$ olarak belirlenmiş ve depolama boyunca ekstrakt ilaveli gruplarda önemli derecede $(P<0.05)$ daha düşük bulunmuştur. TVB-N değerleri 2. günden sonra depolamanın sonuna kadar artış göstermiş ve depolama sonunda japon karidesi kontrol ve yeşil kaplan karidesi kontrol gruplarında sırasi ile 123.29 ve $108.54 \mathrm{mg} / 100 \mathrm{~g}$ olarak en yüksek ( $P$ $<0.05)$ değerlere ulaşmıştır. Soğan kabuğu ekstrakt1 ilave edilen karideslerde TVB-N değerleri depolama boyunca $35 \mathrm{mg} / 100 \mathrm{~g}$ ' geçmemiş ve bu nedenle "pazarlanabilir" özelliğini depolama sonuna kadar korumuştur. Kontrol grupları ise 6. günde bu değeri aşmıştır. Depolama sonunda en düşük TVB-N değeri soğan kabuğu ekstraktı ile muamele edilmiş japon karidesinde $(32.20 \mathrm{mg} / 100 \mathrm{~g})$ gözlenmiştir. 


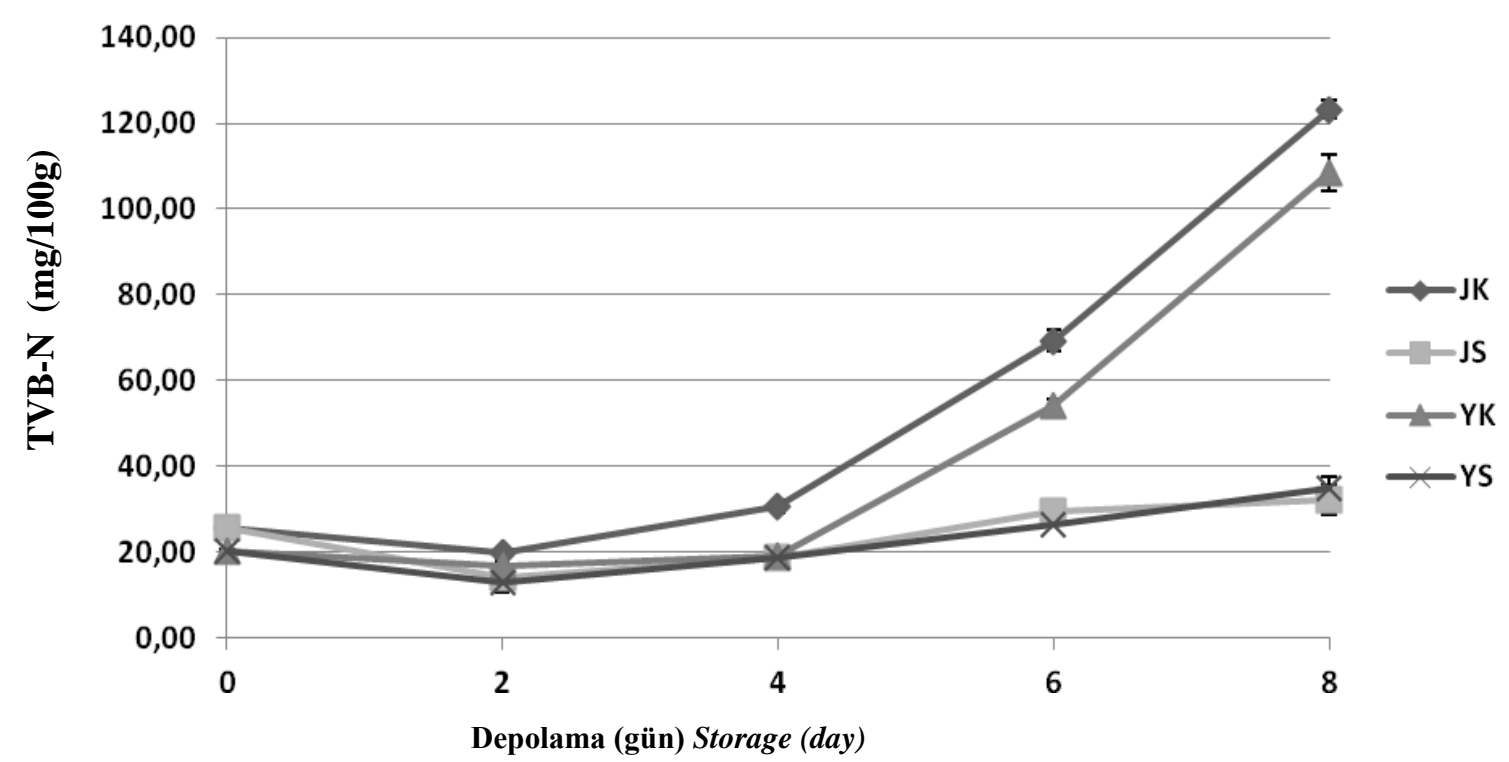

Şekil 1. Japon karidesi ve yeşil kaplan karidesinin depolama süresince toplam uçucu bazik azot (TVBN) değerlerinde meydana gelen değişimler. * JK: japon karidesi kontrol; JS: soğan kabuğu ekstraktı ile muamele edilmiş japon karidesi; YK: yeşil kaplan karidesi kontrol; YS: soğan kabuğu ekstraktı ile muamele edilmiş yeşil kaplan karidesi

Figure 1. Changes in total volatile basic nitrogen (TVB-N) values of japanese and green tiger shrimp during storage period.* JK: japanese shrimp control; JS: japanese shrimp treated with onion peel extract; YK: green tiger shrimp control; YS: green tiger shrimp treated with onion peel extract

Balıklardaki bakteriyel bozulma ve endojen enzimlerin aktivitesi ile beraber TVB-N miktar1 artış göstermektedir. TVB-N analizi balığın tazeliğinin belirlenmesinde yaygin olarak kullanılan yöntemlerden biri olup (Lang, 1979; Vareltzis vd., 1997), genel olarak balık ve su ürünlerinde $25 \mathrm{mg} / 100 \mathrm{~g}^{\prime}$ a kadar TVB-N içeren örnekler 'çok iyi', $30 \mathrm{mg} / 100 \mathrm{~g}$ 'a kadar 'iyi', 35 $\mathrm{mg} / 100 \mathrm{~g}$ 'a kadar 'pazarlanabilir' ve 35 $\mathrm{mg} / 100 \mathrm{~g}$ 'dan fazla olanlar ise 'bozulmuş' olarak değerlendirilmektedirler (Huss, 1988). Chinese National standartlarına göre (GB2741-94), taze bir karideste TVB-N değeri $300 \mathrm{mg} / 100 \mathrm{~g}^{\prime} \mathrm{dan}$ düşük olmalıdır.

Patır vd. (2009) tarafından yapılan çalışmada karides etinin başlangıç TVB-N değerinin 18.23 $\mathrm{mg} / 100 \mathrm{~g}$ olduğu bulunurken, Aş1k (2009) tarafindan sarımsak yağ1 içeren kitosan bazlı yenilebilir filmlerle kaplanan karideslerin TVB-N değerleri başlangiçta $20.72 \mathrm{mg} / 100 \mathrm{~g}$ olarak bildirilmiştir. Soğukta depolanan karideslerin TVB-N değerleri depolamanın başında Varlık vd.
(2000) tarafindan $22.95 \mathrm{mg} / 100 \mathrm{~g}$ olarak bulunmuştur. Ayrıca Kalıştır (2008), karides marinatları ile yaptığ1 çalışmada TVB-N değerlerinin marinat işlemi öncesinde 15.97 $\mathrm{mg} / 100$ olduğunu rapor etmişlerdir. Hocaoğlu vd. (2012) tarafindan yapilan bir çalışmada gamma ışınlama işlemi yapılan ve $-18^{\circ} \mathrm{C}^{\prime}$ de 3 ay boyunca depolanan karideslerde kontrol grubunda TVB-N değerini depolamanın başında $9.41 \mathrm{mg} / 100 \mathrm{~g}$ olarak bulmuş ve depolama süresince dalgalanma gösteren bu değer depolamanın sonunda 12.33 $\mathrm{mg} / 100 \mathrm{~g}$ değerine ulaşmıstır. Jelatin bazlı portakal yaprağı uçucu yağı ile muamele ettikleri karides etinde kontrol grubunda başlangıç TVB$\mathrm{N}$ değerini $17.14 \mathrm{mg} / 100 \mathrm{~g}$ bulan Alparslan vd. (2016), depolama süresince artış gösteren bu değerin depolamanın sonunda (12. gün) 41.27 $\mathrm{mg} / 100 g^{\prime} a$ çıktığını tespit etmişlerdir. Mevcut çalışmadan elde edilen sonuçlar depolama boyunca tüm örneklerde TVB-N değerlerinde artış gözlendiğini göstermiş olup benzer sonuçlar Varlık vd. (2000), Sadok vd. (2004), Bilgin vd. (2006) tarafindan da rapor edilmiştir. 


\section{Depolama boyunca TBARS değerinde} meydana gelen değişimler

TBA değeri balık ve balık ürünlerinde koku, lezzet, tekstür ve renkte değişikliklerine yol açabilen lipit oksidasyonu derecesinin belirlenmesinde yaygin olarak kullanılmaktadır (Wenjiavd., 2013). Karides etinde 8 günlük depolama süresince TBARS değerlerinde meydana gelen değişimler Şekil 2'de verilmiştir. Depolamanın başında japon karidesi ve yeşil kaplan karidesinde TBARS değerleri sırası ile 0.78 ve $0.91 \mathrm{mg} \mathrm{MA} / \mathrm{kg}$ olarak bulunmuştur. $\mathrm{Bu}$ değerler depolamanın sonuna kadar artış göstermiş ve 8 . günde sıras1 ile 1.78 ve 1.62 mgMA/kg’a yükselmiştir. Depolama süresince önemli derecede $(P<0.05)$ en yüksek değerler her iki karides grubunda da kontrol örneklerinde gözlenmiştir. Soğan kabuğu ile ekstrakte edilmiş japon karidesinde depolama sonunda 1.27 mgMA/kg olarak gözlenen TBARS değeri yeşil kaplan karidesinde $1.18 \mathrm{mgMA} / \mathrm{kg}$ olarak bulunmuştur. Kontrol grupları ile kiyaslandığında soğan kabuğu ile ekstrakte edilen örneklerde daha düşük gözlenen TBARS değerleri, soğan kabuğu ekstraktının lipit oksidasyonu üzerinde etkili olduğunu göstermektedir.

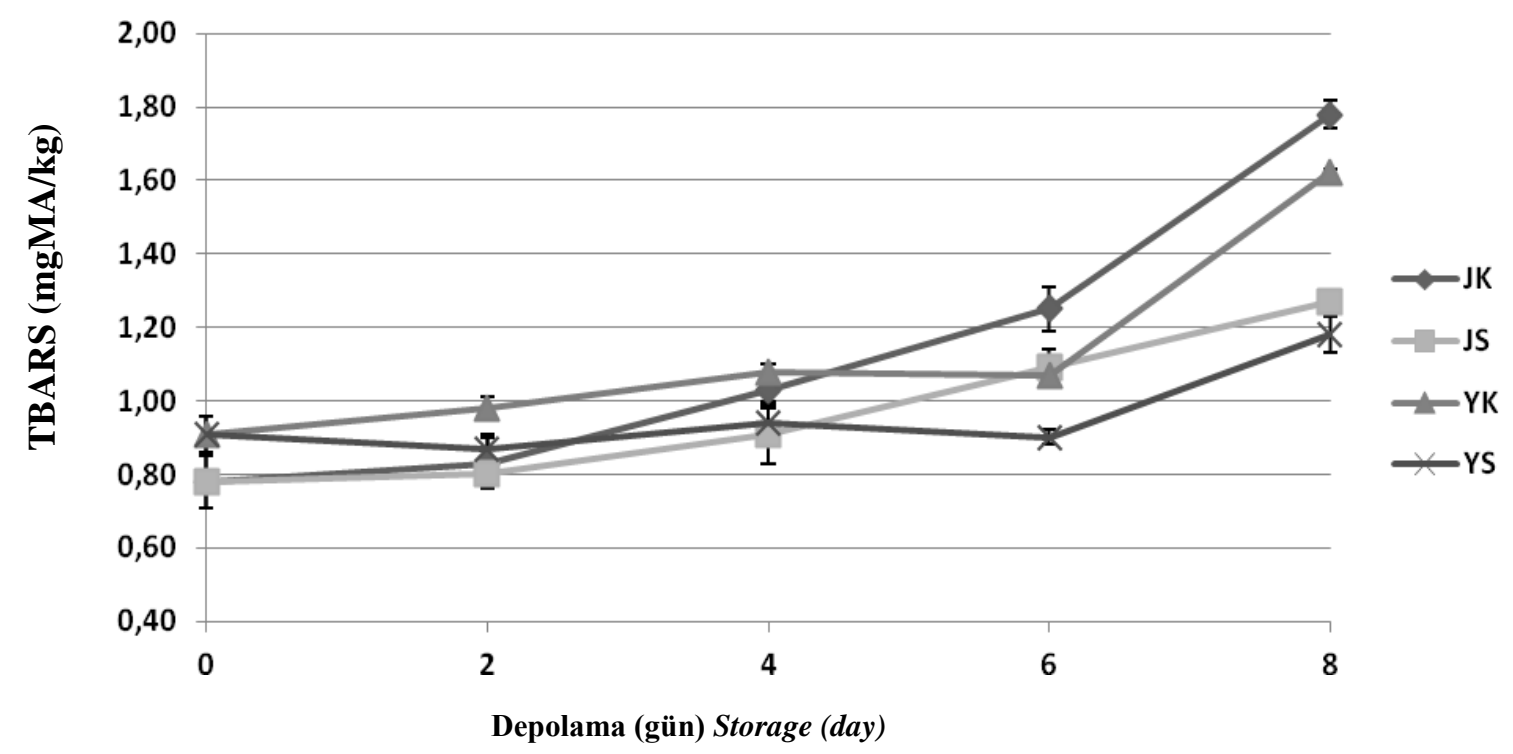

Şekil 2. Japon karidesi ve yeşil kaplan karidesinin depolama süresince tiyobarbitürikasit (TBARS) değerlerinde meydana gelen değişimler.* JK: japon karidesi kontrol; JS: soğan kabuğu ekstraktı ile muamele edilmiş japon karidesi; YK: yeşil kaplan karidesi kontrol; YS: soğan kabuğu ekstraktı ile muamele edilmiş yeşil kaplan karidesi

Figure 2. Changes in thiobarbituric acid (TBARS) values of japanese and green tiger shrimp during storage period. * JK: japanese shrimp control; JS: japanese shrimp treated with onion peel extract; YK: green tiger shrimp control; YS: green tiger shrimp treated with onion peel extract

Aşık (2009) sarımsak yağı içeren kitosan kaplama ile kapladıkları karideslerde 0 . gün TBARS değerini $0.35 \mathrm{mgMA} / \mathrm{kg}$ olarak bulmuşlardır. Cadun vd. (2005) antimikrobiyal ajanlar ekleyerek marine edilmiş karideste kalite değişimlerini incelemişlerdir. Başlangıçta karides etinde TBARS değerini $0.51 \mathrm{mgMA} / \mathrm{kg}$ olarak rapor etmişlerdir ve depolama süresince bu değerin marine edilmiş karideslerde önemli derecede artış gösterdiğini gözlemlemişlerdir.

\section{Depolama boyunca $\mathrm{pH}$ değerinde meydana gelen değişimler}

Soğan kabuğu ekstraktı ile muamele edilmiş karides etinin depolama boyunca $\mathrm{pH}$ değerlerinde meydana gelen değişim Şekil 3'de verilmiştir. Başlangiç $\mathrm{pH}$ değeri japon karidesinde 7.26 ve 
yeşil kaplan karidesinde 7.13 olarak gözlenmiştir. Her iki karides türünde de kontrol gruplarının $\mathrm{pH}$ değerleri soğan kabuğu ekstraktı ile muamele edilen grupların $\mathrm{pH}$ değerlerinde önemli düzeyde $(P<0.05)$ daha yüksek bulunmuştur. Depolama sonunda en yüksek $\mathrm{pH}$ değerleri sırası ile 8.30 ve 7.82 olarak japon karidesi kontrol ve yeşil kaplan karidesi kontrol gruplarında gözlenmiştir. Soğan Șekil 3 kabuğu ekstraktı ile muamele edilmiş japon karidesi ve yeşil kaplan karidesi gruplarında $\mathrm{pH}$ değerleri depolama sonunda sirası ile 7.20 ve 7.0 olarak bulunmuştur. Karides etinde $\mathrm{pH}$ değerinin genellikle 7.0-7.3 arasında değiştiği, depolama koşullarına bağlı olarak depolama süresince 7.57.7'ye kadar yükseldiği bildirilmektedir (Bayizit vd., 2003).

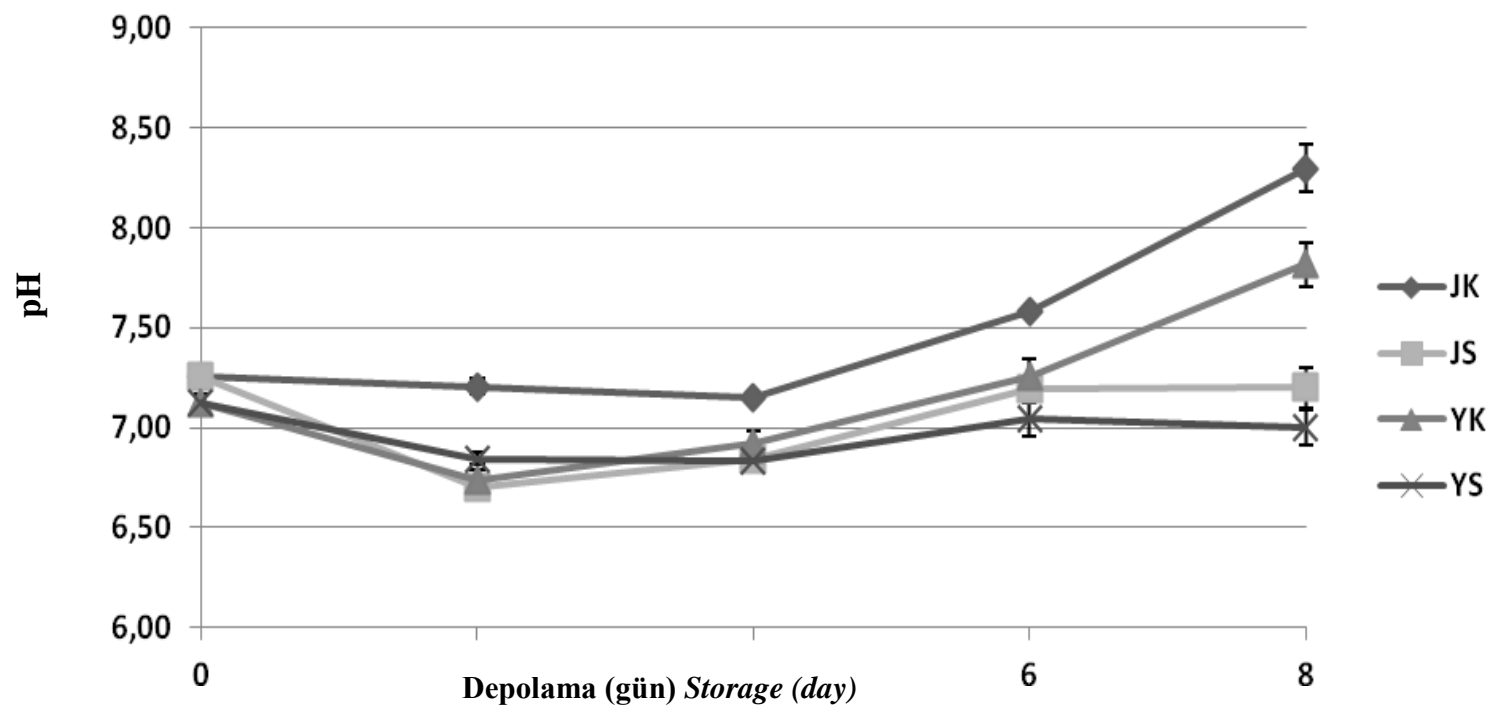

Şekil 3. Japon karidesi ve yeşil kaplan karidesinin depolama süresince $\mathrm{pH}$ değerlerinde meydana gelen değişimler.* JK: japon karidesi kontrol; JS: soğan kabuğu ekstraktı ile muamele edilmiş japon karidesi; YK: yeşil kaplan karidesi kontrol; YS: soğan kabuğu ekstraktı ile muamele edilmiş yeşil kaplan karidesi Figure 3. Changes in $p H$ values of japanese and green tiger shrimp during storage period. * JK: japanese shrimp control; $J S:$ japanese shrimp treated with onion peel extract; YK: green tiger shrimp control; YS: green tiger shrimp treated with onion peel extract

Kontrol gruplarında depolama sonunda $\mathrm{pH}$ değerlerinde gözlenen artışlar benzer çalışmalarda da gözlenmiştir. Zeng vd. (2005) farklı sicakliklarda $\left(-1.5\right.$ ve $\left.+1.5^{\circ} \mathrm{C}\right)$ depoladıkları karides etinde (Pandalus borealis) $\mathrm{pH}$ değerini başlangıçta 7.41 olarak tespit etmişlerdir. Depolama sonunda $1.5^{\circ} \mathrm{C}^{\prime}$ de depolanan örneklerin $\mathrm{pH}$ değerlerinin 8.26 ve $-1.5^{\circ} \mathrm{C}^{\prime}$ de depolanan örneklerin $\mathrm{pH}$ değerlerinin 7.98 olduğunu rapor etmişlerdir. Bir başka çalışmada buzdolabı koşullarında $\left(4^{\circ} \mathrm{C}\right)$ depolanan kahverengi karideslerin (Crangon crangon) $\mathrm{pH}$ değerleri depolamanın başında 6.83 olarak gözlenirken, depolamanın sonunda (5.gün) 7.95 olarak bulunmuştur (Bilgin vd., 2006). Çolakoğlu vd. (2006) taze karides etinde (Parapenaus longirostris) $\mathrm{pH}$ değerinin başlangiçta 7.60 olduğunu bildirirken, depolamanın 5 . gününde bu değerin 8.06'ya çıktığını tespit etmişlerdir. Yapılan diğer çalışmalar depolama sonunda karides etinde artış gösteren $\mathrm{pH}$ değerlerinin mevcut çalışmayı desteklediğini göstermektedir. Alparslan vd. (2016)'nin yaptığ1 çalışmada jelatin kaplama uygulanan karides örneklerinin kontrol grubunda başlangiçta $\mathrm{pH}$ değerini 6.47 olarak belirlerken, depolamanın sonuna kadar artış gösteren $\mathrm{pH}$ değeri depolama sonunda (14. gün) 8.55 olarak bulunmuştur. 


\section{Depolama Esnasinda Meydana Gelen Mikrobiyolojik Değişimler}

Depolama boyunca soğan kabuğu ekstraktı ile muamele edilmiş japon karidesi ve yeşil kaplan karidesinin toplam mezofilik aerobik canlı sayısında meydana gelen değişim Şekil 4'te verilmiştir. Depolama başında toplam canlı sayısı japon karidesi ve yeşil kaplan karidesinde sırası ile 2.95 ve $2.68 \mathrm{log} \mathrm{kob} / \mathrm{g}$ olarak belirlenmiştir. Tüm gruplarda artış gösteren toplam canlı sayısı depolama sonunda 4.74 ve $4.83 \mathrm{log} \mathrm{kob} / \mathrm{g}$ olarak sırası ile japon karidesi ve yeşil kaplan karidesi kontrol gruplarında gözlenmiştir. Soğan kabuğu ekstraktı ile muamele edilen karideslerde toplam canlı sayısı kontrol gruplarından önemli derecede $(P<0.05)$ daha düşük bulunmuştur. En düşük bakteri sayis1 ekstrakt ile muamele edilen karideslerde gözlemlenmiş ve depolama sonunda japon karidesi ve yeşil kaplan karidesinde sırası ile 4.57 ve $3.77 \mathrm{log} \mathrm{kob} / \mathrm{g}$ olmuştur. Toplam psikrofilik canlı sayısı başlangıçta japon karidesi ve yeşil kaplan karidesinde sirası ile 3.28 ve $2.95 \mathrm{log}$ $\mathrm{kob} / \mathrm{g}$ olarak tespit edilmiştir (Şekil 5). Psikrofil canlı sayısı tüm gruplarda depolama boyunca artış göstermiş ve esktrakt ile muamele edilen gruplarda daha düşük düzeyde $(P<0.05)$ tespit edilmiştir. Depolama sonunda toplam psikrofil canlı sayıs1 ekstrakt uygulanan japon ve yeşil kaplan karidesinde sirası ile 6.48 ve $5.73 \log \mathrm{kob} / \mathrm{g}$ olarak gözlenmiştir. Japon karidesi kontrol grubunda depolama sonunda toplam psikrofilik canlı sayıs1 7.28 log kob/g değerine ulaşırken, yeșil kaplan karidesi kontrol grubu $6.27 \log \mathrm{kob} / \mathrm{g}$ değerine ulaşmışır.

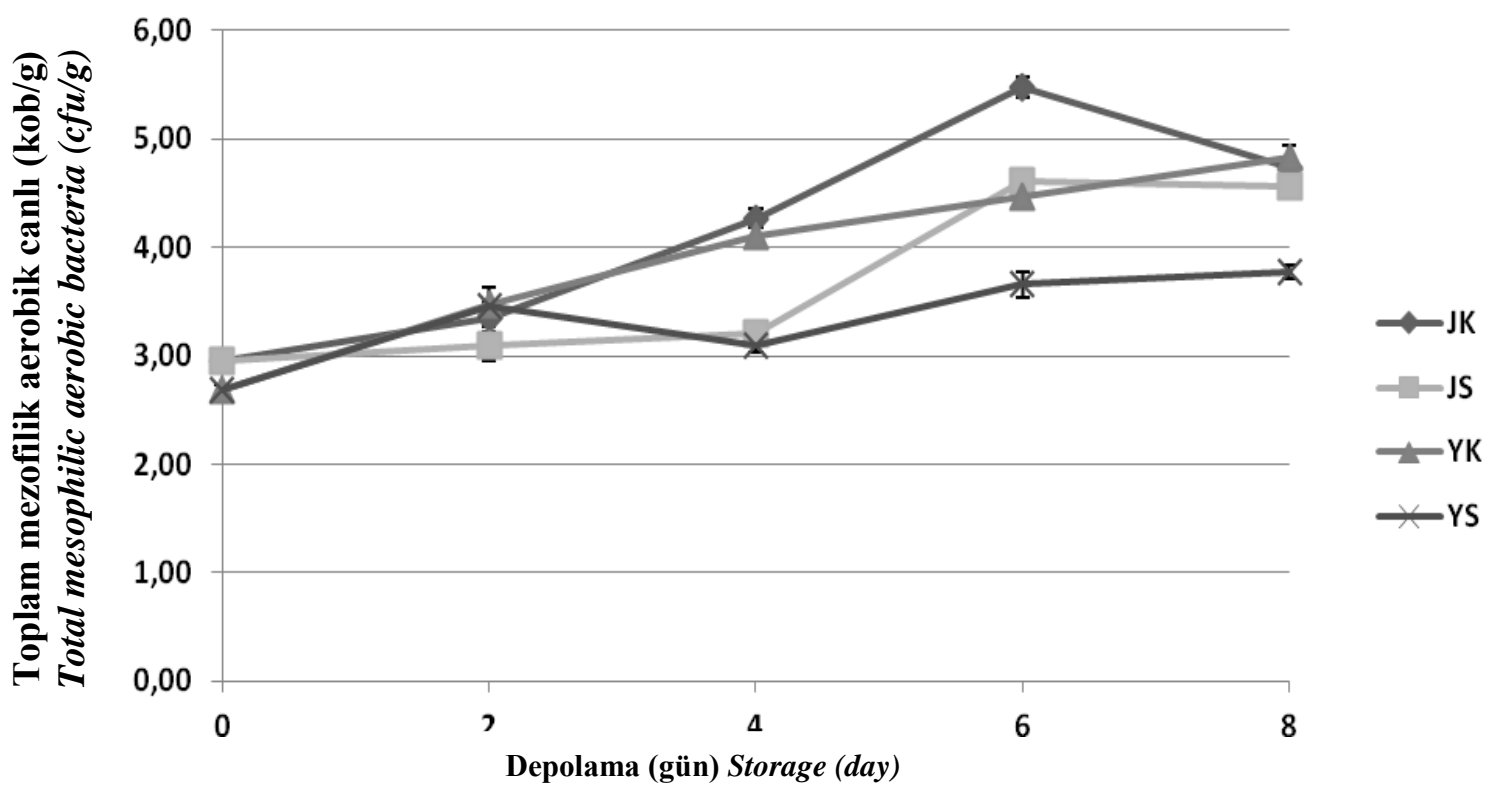

Şekil 4. Japon karidesi ve yeşil kaplan karidesinin depolama süresince toplam mezofilik aerobik canlı sayısında meydana gelen değişimler.* JK: japon karidesi kontrol; JS: soğan kabuğu ekstraktı ile muamele edilmiş japon karidesi; YK: yeşil kaplan karidesi kontrol; YS: soğan kabuğu ekstraktı ile muamele edilmiş yeşil kaplan karidesi

Figure 4. Changes in total mesophilic aerobic bacteria number of japanese and green tiger shrimp during storage period.* JK: japanese shrimp control; JS: japanese shrimp treated with onion peel extract; YK: green tiger shrimp control; YS: green tiger shrimp treated with onion peel extract 


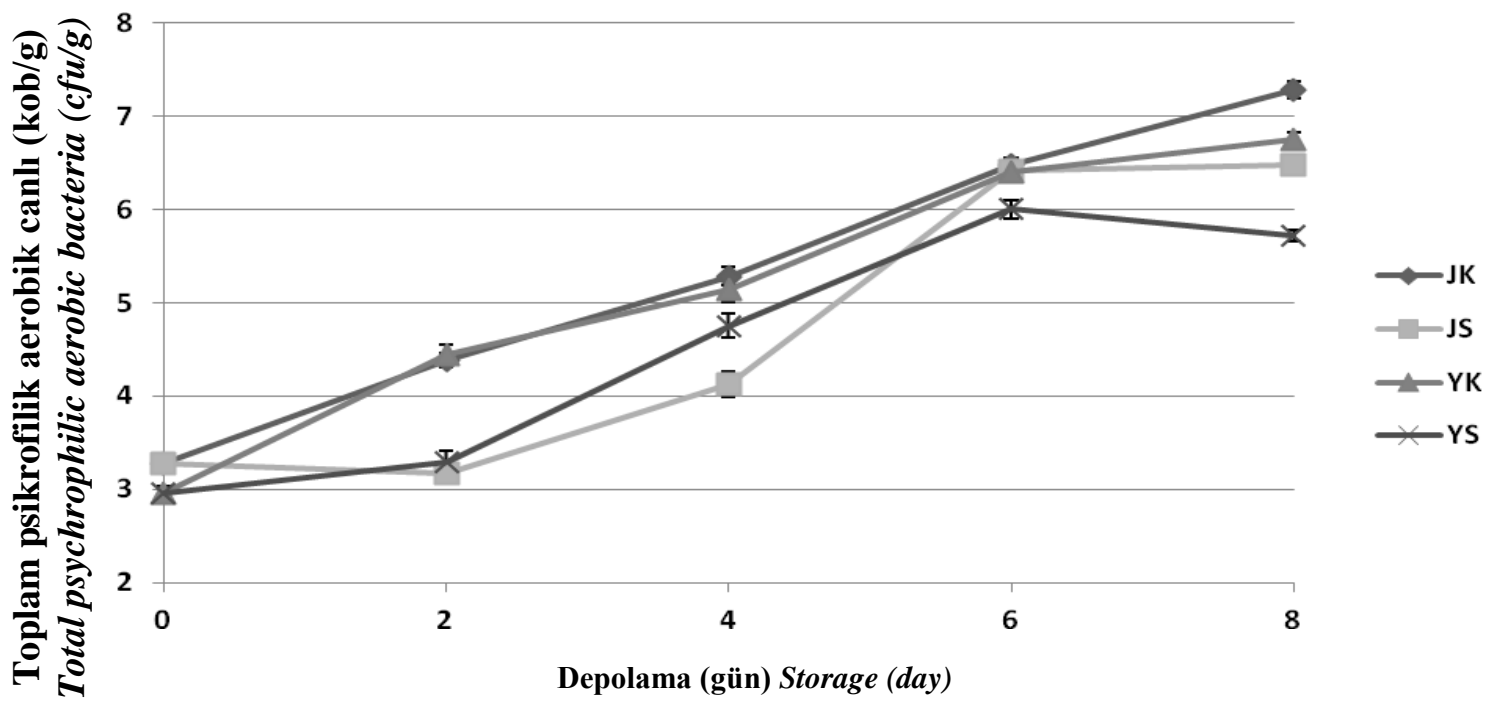

Şekil 5. Japon karidesi ve yeşil kaplan karidesinin depolama süresince toplam psikrofilik canlı sayısında meydana gelen değişimler.* JK: japon karidesi kontrol; JS: soğan kabuğu ekstraktı ile muamele edilmiş japon karidesi; YK: yeşil kaplan karidesi kontrol; YS: soğan kabuğu ekstraktı ile muamele edilmiş yeşil kaplan karidesi

Figure 5. Changes in total psychrophilic bacteria number of japanese and green tiger shrimp during storage period. ${ }^{*} J K$ : japanese shrimp control; JS: japanese shrimp treated with onion peel extract; YK: green tiger shrimp control; YS: green tiger shrimp treated with onion peel extract

Karideslerde kalitenin belirlenmesinde duyusal ve kimyasal kalite analizlerinin yanında mikrobiyal değerlendirme de büyük önem taşımaktadır (Sivertsvik ve Birkeland, 2006). Zeng vd. (2005) soğukta depolanan karideslerde toplam canlı sayısını $2.4 \times 10^{5} \mathrm{kob} / \mathrm{g}$ olarak rapor etmişler ve depolama boyunca artış göstererek depolama sonunda (7. gün) $3 \times 10^{8} \mathrm{kob} / \mathrm{g}$ a çıtı̆̆ını bildirmişlerdir. Wang vd. (2018) karvakrol ilaveli kitosan bazlı yenilebilir filmlerle kapladıkları karidesleri buzda 10 gün süreyle depolamışlardır. Karideslerde toplam canlı sayisinin depolama süresince artış gösterdiğini ancak kaplama yapılan karideslerde bu değerin kontrol grubundan önemli derecede düşük düzeyde artış gösterdiğini bildirmişlerdir. Bir başka çalışmada Farajzadeh vd. (2016) jelatin ve kitosan bazlı yenilebilir filmlerle kapladıkları karideslerde toplam bakteri sayısını depolama başlangıcında $2.5 \mathrm{log} \mathrm{kob} / \mathrm{g}$ olarak bulmuşlardır. Kontrol grubunda toplam canlı sayısının depolamanın 8. gününde limit değer olarak kabul edilen (ICMSF, 1986) 7 log kob/g'1 aştığ1, kaplama yapilan gruplarda ise 14 . günde bu değere ulaşıldığ1 görülmüştür. Aynı çalıșmada toplam psikrofilik canlı sayısının da kontrol grubunda kaplama yapilan gruplara göre daha yüksek düzeyde olduğu ve depolamanın 8 . gününde kontrol ile diğer gruplar arasında toplam psikrofilik canlı sayısı bakımından yaklaşık $4.5 \mathrm{log}$ $\mathrm{kob} / \mathrm{g}$ fark olduğu tespit edilmiştir. Sae-leaw ve Benjakul (2019) farklı konsantrasyonlarda kaju yaprağ1 ekstraktı ile muamele ettikleri karideslerde 12 günlük depolama boyunca kalite değişimlerini gözlemlemişlerdir. Toplam canlı sayısı ve toplam psikrofilik canlı sayısının ekstrakt ile muamale edilen gruplarda kontrol grubuna göre daha düşük olduğunu bildirmişlerdir. Yapılan tüm çalışmalar karideslerde mikrobiyal kalitenin korunmasinda doğal katkı maddelerinin etkili olduğunu ve mevcut çalışmada gözlenen sonuçları desteklediği görülmektedir.

\section{Duyusal kalitede meydana gelen değişimler}

Su ürünlerinin tazeliğinin ve kalitesinin belirlenmesinde duyusal değerlendirme en güvenilir kriterlerden birisidir. Soğan kabuğu ekstraktı ile muamele edilmiş taze karideslerin duyusal özelliklerinde meydana gelen değişimler 
Çizelge 1.'de verilmiştir. Kontrol grupları ve soğan kabuğu ekstraktı ile muamele edilmiş karidesler arasında koku, tekstür, renk, görünüş ve genel beğeni özellikleri yönünden depolama boyunca istatistiksel olarak önemli düzeyde $(P$ $<0.05)$ farklılıklar bulunmuştur. Depolama süresi ilerledikçe kontrol gruplarının duyusal parametrelerinde düşüş olduğu gözlenmiş ve bu gruplar, soğan kabuğu ekstraktı ile muamele edilmiş karides grupları ile kıyaslandığında depolama boyunca panelistlerden daha düşük puanlar almıştır. Her iki karides türünde de kontrol grupları depolamanın 4. gününde duyusal olarak reddedilmiş, ancak soğan kabuğu ekstraktı ilaveli gruplar depolama sonuna kadar kabul edilebilir özelliğini korumuştur. Aşık (2009) sarımsak yağ1 içeren kitozan bazlı kaplamalarla kaplanan karideslerin duyusal değerlendirmesinde benzer sonuçlar elde etmiştir. Bu çalışmadan elde edilen duyusal veriler doğrultusunda, soğan kabuğu ekstraktının japon karidesi ve yeşil kaplan karidesinde raf ömrünün uzatılmasında etkili olduğu tespit edilmiştir.

Çizelge 1. Japon karidesi ve yeşil kaplan karidesinin depolama süresince duyusal özelliklerinde meydana gelen değişimler.* JK: japon karidesi kontrol; JS: soğan kabuğu ekstraktı ile muamele edilmiş japon karidesi; YK: yeşil kaplan karidesi kontrol; YS: soğan kabuğu ekstraktı ile muamele edilmiş yeşil kaplan karidesi

Table 1. Changes in sensory properties of japanese and green tiger shrimp during storage period. ${ }^{*} J K:$ japanese shrimp control; JS: japanese shrimp treated with onion peel extract; YK: green tiger shrimp control; YS: green tiger shrimp treated with onion peel extract

\begin{tabular}{|c|c|c|c|c|c|}
\hline & $\mathrm{JK}$ & JS & YK & YS & $\begin{array}{c}\text { Depolama (gün) } \\
\text { Storage (days) }\end{array}$ \\
\hline \multirow{5}{*}{$\begin{array}{l}\text { Koku } \\
\text { (odor) }\end{array}$} & $9.00 \pm 0.00^{\mathrm{Aa}}$ & $9.00 \pm 0.00^{\mathrm{Aa}}$ & $9.00 \pm 0.00^{\mathrm{Aa}}$ & $9.00 \pm 0.00^{\mathrm{Aa}}$ & 0 \\
\hline & $5.80 \pm 0.75^{\mathrm{Bb}}$ & $7.60 \pm 0.49 \mathrm{Abc}$ & $6.00 \pm 0.63^{\mathrm{Bb}}$ & $8.20 \pm 0.40^{\mathrm{Ab}}$ & 2 \\
\hline & $2.25 \pm 0.43^{\mathrm{Cc}}$ & $8.00 \pm 0.00^{\mathrm{Ab}}$ & $2.75 \pm 0.83^{\mathrm{Cc}}$ & $6.75 \pm 0.43^{\mathrm{Bc}}$ & 4 \\
\hline & $1.50 \pm 0.50^{\mathrm{Bd}}$ & $7.25 \pm 0.43^{\mathrm{Ac}}$ & $1.00 \pm 0.00^{\mathrm{Bd}}$ & $6.75 \pm 0.43^{\mathrm{Ac}}$ & 6 \\
\hline & $1.00 \pm 0.00^{\mathrm{Cd}}$ & $3.25 \pm 0.43^{\mathrm{Bd}}$ & $1.00 \pm 0.00^{\mathrm{Cd}}$ & $4.25 \pm 0.43^{\mathrm{Ad}}$ & 8 \\
\hline \multirow{5}{*}{$\begin{array}{l}\text { Tekstür } \\
\text { (texture) }\end{array}$} & $9.00 \pm 0.00^{\mathrm{Aa}}$ & $9.00 \pm 0.00^{\mathrm{Aa}}$ & $9.00 \pm 0.00^{\mathrm{Aa}}$ & $9.00 \pm 0.00^{\mathrm{Aa}}$ & 0 \\
\hline & $4.60 \pm 0.80^{\mathrm{Bbc}}$ & $7.20 \pm 0.40^{\mathrm{Abc}}$ & $5.60 \pm 0.49^{\mathrm{Bb}}$ & $8.00 \pm 0.89 \mathrm{Ab}$ & 2 \\
\hline & $5.50 \pm 1.50^{\mathrm{Bb}}$ & $7.50 \pm 0.50^{\mathrm{Ab}}$ & $3.25 \pm 0.43 \mathrm{Cc}$ & $6.50 \pm 0.50^{\mathrm{ABc}}$ & 4 \\
\hline & $3.25 \pm 0.83 \mathrm{Bcd}$ & $6.75 \pm 0.43^{\mathrm{Ac}}$ & $3.50 \pm 0.50^{\mathrm{Bc}}$ & $7.00 \pm 0.00^{\mathrm{Ac}}$ & 6 \\
\hline & $2.25 \pm 0.83^{\mathrm{Bd}}$ & $4.50 \pm 0.50^{\mathrm{Ad}}$ & $2.50 \pm 0.50^{\mathrm{Bd}}$ & $4.25 \pm 0.43^{\mathrm{Ad}}$ & 8 \\
\hline \multirow{5}{*}{$\begin{array}{l}\text { Renk } \\
\text { (color) }\end{array}$} & $9.00 \pm 0.00^{\mathrm{Aa}}$ & $9.00 \pm 0.00^{\mathrm{Aa}}$ & $9.00 \pm 0.00^{\mathrm{Aa}}$ & $9.00 \pm 0.00^{\mathrm{Aa}}$ & 0 \\
\hline & $5.40 \pm 0.49^{\mathrm{Bb}}$ & $7.40 \pm 0.49 \mathrm{Abc}$ & $5.20 \pm 0.40^{\mathrm{Bb}}$ & $7.40 \pm 0.49 \mathrm{Ab}$ & 2 \\
\hline & $5.25 \pm 1.30^{\mathrm{Bb}}$ & $7.75 \pm 0.43^{\mathrm{Ab}}$ & $3.25 \pm 0.43 \mathrm{Cc}$ & $6.50 \pm 0.50 \mathrm{ABc}$ & 4 \\
\hline & $3.25 \pm 0.43^{\mathrm{Dc}}$ & $6.75 \pm 0.43^{\mathrm{Bc}}$ & $4.00 \pm 0.00^{\mathrm{Cc}}$ & $7.50 \pm 0.50^{\mathrm{Ab}}$ & 6 \\
\hline & $1.50 \pm 0.50^{\mathrm{Bd}}$ & $5.00 \pm 1.00^{\mathrm{Ad}}$ & $3.00 \pm 1.22^{\mathrm{Bc}}$ & $5.00 \pm 0.71 \mathrm{Ad}$ & 8 \\
\hline \multirow{5}{*}{$\begin{array}{l}\text { Görünüş } \\
\text { (apperance) }\end{array}$} & $9.00 \pm 0.00^{\mathrm{Aa}}$ & $9.00 \pm 0.00^{\mathrm{Aa}}$ & $9.00 \pm 0.00 \mathrm{Aa}$ & $9.00 \pm 0.00 \mathrm{Aa}$ & 0 \\
\hline & $5.40 \pm 0.49^{\mathrm{Bb}}$ & $7.60 \pm 0.49 \mathrm{Ab}$ & $5.20 \pm 0.40^{\mathrm{Bb}}$ & $8.20 \pm 0.75^{\mathrm{Ab}}$ & 2 \\
\hline & $4.25 \pm 0.43^{\mathrm{Bc}}$ & $7.25 \pm 0.43^{\mathrm{Ab}}$ & $4.50 \pm 0.50^{\mathrm{Bbc}}$ & $7.50 \pm 0.50^{\mathrm{Abc}}$ & 4 \\
\hline & $3.25 \pm 0.43^{\mathrm{Bd}}$ & $6.25 \pm 0.43^{\mathrm{Ac}}$ & $3.75 \pm 0.83 \mathrm{Bcd}$ & $6.75 \pm 0.43^{\mathrm{Ac}}$ & 6 \\
\hline & $1.00 \pm 0.00 \mathrm{Ce}$ & $4.75 \pm 0.43^{\mathrm{Ad}}$ & $2.50 \pm 1.12^{\mathrm{Bd}}$ & $5.25 \pm 0.43^{\mathrm{Ad}}$ & 8 \\
\hline \multirow{5}{*}{$\begin{array}{l}\text { Genel } \\
\text { beğeni } \\
\text { (general } \\
\text { acceptance) }\end{array}$} & $9.00 \pm 0.00^{\mathrm{Aa}}$ & $9.00 \pm 0.00 \mathrm{Aa}$ & $9.00 \pm 0.00^{\mathrm{Aa}}$ & $9.00 \pm 0.00^{\mathrm{Aa}}$ & 0 \\
\hline & $5.00 \pm 0.89^{\mathrm{Bb}}$ & $7.40 \pm 0.49 \mathrm{Abc}$ & $5.60 \pm 0.49^{\mathrm{Bb}}$ & $7.80 \pm 0.40^{\mathrm{Ab}}$ & 2 \\
\hline & $3.75 \pm 0.83^{\mathrm{Bc}}$ & $7.75 \pm 0.43^{\mathrm{Ab}}$ & $3.00 \pm 1.22^{\mathrm{Bd}}$ & $6.25 \pm 0.83^{\mathrm{Ac}}$ & 4 \\
\hline & $2.75 \pm 0.43^{\mathrm{Cd}}$ & $7.00 \pm 0.00^{\mathrm{Ac}}$ & $4.00 \pm 0.00^{\mathrm{Bc}}$ & $7.00 \pm 0.71^{\mathrm{Abc}}$ & 6 \\
\hline & $1.25 \pm 0.43 \mathrm{Ce}$ & $4.50 \pm 0.50^{\mathrm{Ad}}$ & $2.50 \pm 0.50^{\mathrm{Bd}}$ & $5.25 \pm 0.43^{\mathrm{Ad}}$ & 8 \\
\hline
\end{tabular}

Aynı satırlar arasındaki istatistiksel fark $(P<0.05)$ büyük harflerle, aynı sütunlar arasındaki istatistiksel fark $(P<0.05)$ küçük harflerle gösterilmiştir.

Means indicated by different capital letters in the same row differ significantly $(P<0.05)$. Means indicated by different lowercase letters in the same column differ significantly $(P<0.05)$. 


\section{SONUÇ}

Karidesler bozulmaya karşı son derece hassas su ürünleridir. $\mathrm{Bu}$ nedenle son zamanlarda raf ömürlerinin arttırılması ve kalitelerinin korunmasına yönelik arayışlar da gittikçe önem kazanmaktadır. Bu çalışma bulgularına dayanarak, bir gida atığ1 olan ve güçlü antioksidan ve antimikrobiyal özelliğe sahip soğan kabuğunun karideslerde kalitenin korunmasında etkili bir doğal materyal olabileceği söylenebilir. 8 günlük depolama süresince soğan kabuğu ekstraktı ile muamele edilen japon karidesi ve yeşil kaplan karidesinde hem fiziko-kimyasal parametreler bakımından hem de mikrobiyal kalite açısından daha düşük değerler elde edilmiştir. Ayrıca duyusal olarak soğan kabuğu ekstraktı uygulanan karideslerin 8. güne kadar kabul edilebilir olduğu görülmüştür.

\section{KAYNAKLAR}

Alparslan, Y., Hasanhocaoglu Yapıc1, H., Metin, C., Baygar, T., Günlü, A., Baygar. T. (2016). Quality assessment of shrimps preserved with orange leaf essential oil incorporated gelatin. LWT-Food Sci Technol, 72: 457-466.

Amerina, M.A., Pangborn, R.V., Roessler, E.B. (1965). Principles of sensory evaluation of food. New York: Academic Press, p. 602.

Arancibia, M.Y., Lopez-Caballero, M.E., GomezGuillen, M.C., Montero, P. (2015). Chitosan coatings enriched with active shrimp waste for shrimp preservation. Food Control, 54: 259-266.

Aşık, E., Candoğan, K. (2014). Effects of chitosan coatings incorporated with garlic oil on quality characteristics of shrimp. J Food Quality, 37: 237246.

Aşık, E. (2009). Sarımsak Yağı İçeren Kitozan Kaplamalarının Karideslerin Kalite Özellikleri Üzerine Etkisi. Ankara Üniversitesi Fen Bilimleri Enstitüsü, Yüksek Lisans Tezi.

Bayizit, A.A., Yılsay, T.Ö., Yücel, A. (2003). Donmuş karideslerin bazı fiziksel, kimyasal ve mikrobiyolojik özellikleri. Ege Üniversitesi Su Ürünleri Dergisi, 20: 303-312.

Bilgin, S., Erdem, M.E., Duyar, H.A. (2006). Pişmiş ve çiğ olarak buzdolabı sıcaklığında muhafaza edilen kahverengi karides' in, Crangon crangon (Linnaeus, 1758), kimyasal kalite değişimleri. Furat Üniv Fen ve Müh Bil Der, 18 (2): 171-179.

Cadun, A., Çaklı, Ş., Kışla, D. (2005). A study of marination of deepwater pink shrimp (Parapenaeus longirostris, Lucas, 1846) and its shelf life. Food Chem, 90: 53-59.

Chinese National Standard (GB2741-94). (1994). Hygienic standard for sea shrimp. Beijing: Chinese National Hygiene Ministry.

Cook N.C, Samman S. (1996). Flavonoidschemistry, metabolism, cardioprotective effects, and dietary sources. J Nutr Biochem, 7(2): 66-76.

Çolakoğlu, F.A., Ormanc1, H.B., Altın, A. (2006). Frische-Star ile Muamele Edilmiş Taze Karideslerin (Parapenaus longirostris) Raf Ö̉mrünün Saptanması Üzerine Bir Araştırma. E.Ü. Su Ürünleri Dergisi, 23(1/3): 383-386.

Farajzadeh, F., Motamedzadegan, A., Shahidi, S.A., Hamzeh, S. (2016). The effect of chitosangelatin coating on the quality of shrimp (Litopenaeus vannamer) under refrigerated condition. Food Control, 67: 163-170.

Gokoglu, N., Yerlikaya, P. (2008). Inhibition effects of grape seed extracts on melanosis formation inshrimp (Parapenaeus longirostris). Int J Food Sci Technol, 43: 1004-1008.

Hocaoglu, A., Demirci, A.S., Gumus, T., Demirci, M. (2012). Effects of gamma irradiation on chemical, microbial quality and shelf life of shrimp. Radiat Phy Chem, 81: 1923-1929.

HUSS, H.H. (1988). Fresh Fish: Quality and Quality Changes. Rome: Food and Agriculture Organization (FAO) of the United Nations, 132p.

Ifesan, B.O.T. (2017). Chemical Composition of Onion Peel (Allium cepa) and its Ability to Serve as a Preservative in Cooked Beef. Int J Soc Res Methodol, 7(4): 24-35.

(ICMSF) International Commission on Microbiological Specifications for Foods (1986). Sampling plans for fish and shellfish: microorganisms in foods 2, sampling for microbiological analysis: principles and scientific 
applications (2nd Ed) Toronto, Canada: University of Toronto Press, pp: 181-196.

Kalıştır, S. (2008). Marine Edilmiş Çimçim Karidesi (Metapenaeus stebbingl)'nin Buzdolabinda $\left(+4^{\circ} \mathrm{C}\right)$ Depolama Süresince Kimyasal ve Duyusal Kalitesindeki Değişimler. Çukurova Üniversitesi Fen Bilimleri Enstitüsü, Yüksek Lisans Tezi.

Kim, H.J., Jung, S., Yong, H.I., Bae, Y.S., Kang, S.N., Kim, I.S., Jo, C. (2014). Improvement of microbiological safety and sensorial quality of pork jerky by electron beam irradiation and by addition of onion peel extract and barbecue flavor. Radiat Phys Chem, 98: 22-28.

Lang, K. (1979). Der fluchtige basentichstoff (TVB-N) bei im binnenland in der verkehrgebrachten frischen seefischen. Arch Lebensmittelhygiene, 30: 215-217.

Maqsood, S., Benjakul, S. (2011). Retardation of haemoglobin-mediated lipid oxidation of Asian sea bass muscle by tannic acid during iced storage. Food Chem, 124: 1056-1062.

Nile, S.H., Nile, A.S., Keum, Y.S., Sharma, K. (2017). Utilization of quercetin and quercetin glycosides from onion (Allium cepa L.) solid waste as an antioxidant, urease and xanthine oxidase inhibitors. Food Chem, 235: 119-126.

Nirmal, N.P., Benjakul, S. (2011). Inhibition of melanosis formation in Pacific white shrimp by the extract of lead (Leucaena lencocephala) seed. Food Chem, 128(2): 427-432.

Nirmal, N.P., Benjakul, S. (2012). Effect of green tea extract in combination with ascorbic acid on the retardation of melanosis and quality changes of Pacific white shrimp during iced storage. Food Bioprocess Tech, 5(8): 2941-2951.

Patır, B., Öksüztepe, G., Emir Çoban, Ö., Dikici, A. (2009). Dondurulmuş Karides Etinden Hazırlanan Kroketlerin Raf Ömrü. F.Ü Săg Bil Vet Derg, 23(1): 29-37.

Sadok, S., Abdelmoulah, A. El Abed, A. (2004). Combined effect of sepia soaking and temperature on the shelf life of peeled shrimp Penaeus kerathurus. Food Chem, 88: 115-122.
Sae-leaw, T., Benjakul, S. (2019). Prevention of quality loss and melanosis of Pacific white shrimp by cashew leaf extracts. Food Control, 95: 257-266.

Salman, S. (1995). Omurgasız Hayvanlar Biyolojisi. 220s. Zirem Basımevi ve Bilgisayar Merkezi. Antakya

Schormüller, J. (1968). Handbuch der Lebensmittel Chemie. Band III/2 Teil. Tierische Lebensmittel Eier, Fleisch. Berlin, Heidelberg, New York: But-termilch, pp. 1482-1537.

Singh, B.N., Singh, B.R., Singh, R.L., Prakash, D., Singh, D.P., Sarma, B.K., Singh, H.B. (2009). Polyphenolics from various extracts/fractions of red onion (Allium cepa) peel with potent antioxidant and antimutagenic activities. Food Chem Toxico., 47(6): 1161-1167.

Sivertsvik, M., Birkeland, S. (2006). Effects of soluble gas stabilisation, modified atmosphere, gas to product volume ratio and storage on the microbiological and sensory characteris tics of ready-to-eat shrimp (Pandalus borealis). Food Sci Tech Int, 12(5): 445-454.

Tabaraki, R., Heidarizadi, E., Benvidi, A. (2012). Optimization of ultrasonic-assisted extraction of pomegranate (Punica granatum L.) peel antioxidants by response surface methodology. Sep Purif Technol, 98: 16-23.

Tarladgis, B.G., Watts, B.M., Younathan, M.T., Dugan, J.R.L. (1960). A distillation method for the quantitative determination of malonaldehyde in rancid foods. J Am Oil Chemist's Soc, 37:44-48.

Vareltzis, K., Koufidis, D., Gavriilidou, E., Papavergou, E., Vasiliadou, S. (1997). Effectiveness of a natural Rosemary (Rosmarinus officinalis) extract on the stability of filleted and minced fish during frozen storage. Zeitschrift für Lebensmitteluntersuchung und-Forschung A, 205(2): 93 96.

Varlık, C., Baygar, T., Özden, Ö., Erkan, N., Erkan, N.,Metin, S. ( 2000). Soğukta depolanan karideslerin (Parapenaeus longirostris, Lucas 1846) baz1 duygusal, fiziksel ve kimyasal parametrelerinin belirlenmesi. Turk J Vet Anim Sci, 24: 181-185. 
Varlik, C. (1993). Su urunlerinde kalite kontrol ilke ve yontemleri. Grda Teknolojisi Derneği, 17: 1617.

Viera, V.B., Piovesan, N., Rodrigues, J.B., Mello, R. de O., Prestes, R.C., Santos, R.C. V dos., Vaucher, R. de A., Hautrive, T.P., Kubota, E.H. (2017). Extraction of phenolic compounds and evaluation of the antioxidant and antimicrobial capacity of red onion skin (Allium cepa L.). Int Food Res J, 24(3): 990-999.

Wang, Q., Lei, J., Ma, J., Yuan, G., Sun., H. (2018). Effect of chitosan-carvacrol coating on the quality of Pacific whiteshrimp during iced storage as affected by caprylic acid. Int J Biol Macromol, 106: 123-129.

Wenjiao, F., Yongkui, Z., Pan, D., Yuwen, Y. (2013). Effects of chitosan coating containing antioxidant of bamboo leaves on qualitative properties and shelf life of silver carp during chilled storage. Crech J Food Sci, 31(5): 451-456.

Zeng, Q.Z., Thorarinsdottir, K.A., Olafsdottir, G. (2005). Quality changes of shrimp (Pandalus borealis) stored under different cooling conditions. J Food Sci, 70(7): 459-466. 